\title{
《测量信息化管理平台》测量软件桥梁模板在桥梁施工测量过 程中的应用
}

\author{
杨靖 \\ 中铁十七局集团中铁(贵州)市政工程有限公司
}

DOI:10.32629/gmsm.v3i4.790

\begin{abstract}
[摘 要] 随着网络技术的高速发展,在传统测量技术的基础上联机手机APP测量软件已成为一个发展 的趋势和潮流,也为一些传统的测量方法带了革命性的变革。本文结合成都至遵义国家高速公路仁怀至 遵义段第RZTJ-2标段大坪子桥从内业计算、外业放样、技术交底及测量数据复核保存归档一体, 与传 统测量技术进行研究对比, 阐述了“测量信息化管理平台”在桥梁施工放样过程中的技术要点。
\end{abstract}

[关键词] 桥梁施工; 测量; 放样; 软件; 信息化

中图分类号：U445 文献标识码：A

\section{1 测量信息化管理平台主要组 成结构}

“测量信息化管理平台”是我公司 将多个测量软件版本进行整合优化, 再 根据公司实际情况创新升级, 不但有对 全部测量信息集中化管理的平台, 还有 配备的手机端的测量APP, 这样可以服务 于一个整体团队, 也可以做到内业复核、 外业测量整个过程的结合。

软件分为两部分 (A. 手机APP、B. 电 脑端信息处理平台)。

\section{1手机APP端}

放样时打开手机APP, 通过蓝牙连接 全站仪, 进入平台数据库选择本次放样 内容及所需的控制点信息, 完成设站后 开始放样, 在测量放样过程中现场数据 以图形化格式显示在手机APP中, 测量完 成后将实测的测量图形化数据信息及时 传送至电脑端信息处理平台, 由电脑端 人员审核。测量数据不满足精度要求, 信息平台电脑端将实现自动智能报警提 示公司精测中心人员, 公司精测中心及 时提出并给出指导性解决方案, 现场测 量人员根据公司提出的测量问题方案进 行整改, 直到测量数据合格为止, 将测量 问题消弭于现场。数据审核无误后批准 通过即可生成电子版直观明了的图形信
息技术交底。交底数据信息将自动保存 至对应的平台数据库中, 以备后期查看 审阅。

1. 2 电脑端信息处理平台

(1) 项目开工伊始, 各项目测量队 长将各自项目的平、纵等曲线要素以 及各路基、结构物的尺寸参数和审图 记录输入信息平台中报公司精测人员 审核, 公司精测中心人员经过信息平 台计算审核通过后, 以各个分部分项 的形式保存至指定的数据库中。保存 至数据库中的数据均可被调用、查看 和自动生成对应的图形数据, 也可导 入导出CAD图形、Ecxel、TXT、CVS等 数据格式, 以供复核学习及使用。在施 工放样中手机APP只可调用本项目数 据参与放样。

(2) 根据项目测量上传的测量实时 数据, 严格把关审核, 对于有问题的测 量数据, 可实现自动智能报警提示公司 精测中心人员, 公司精测中心及时提出 并给出指导性解决方案, 现场测量人员 根据公司提出的测量问题方案进行整 改, 将测量问题消弭于现场。测量方法 及数据无误后审核通过, 生成电子 (签 字完善后的纸质) 版技术交底, 并保存 归档。

\section{2 工程概况}

大坪子桥为左右幅分离式, 桥梁左 幅6x30米先简支后结构连续T梁, 起点 桩号ZK6+991-ZK7+177, 全长186米; 桥 梁右幅 $8 \times 30$ 米先简支后结构连续 T梁, 起点YK6+900-YK7+146, 全长246米。单 幅桥宽 16.5 米, 包括 0.55 米 (防撞护 栏 $)+15.4$ (车行道 $)+0.55$ (防撞护栏)。桥 面纵坡: $i=2.95 \%$ 。桥梁平面线形: 本桥 位于 $\mathrm{R}=1190 \mathrm{~m}$ 的右偏圆曲线上, 桥面横坡 为单向 $4 \%$, 墩台径向布置。

3 “测量信息化管理平台”软 件在桥梁施工测量中的实际应用

应用 “测量信息化管理平台” 从内 业桩基坐标计算、外业坐标放样、测量 技术交底等方面与传统测量技术进行对 比分析。

\section{1 现场放样}

现场放样首先在合适的位置架设 全站仪, 打开手机APP, 通过蓝牙连接全 站仪进行设站, 设站必须满足规范要求 方能完成。设站完成后在手机APP数据 库中选择桥梁功能, 选择放样内容, 开 始放样, 放样过程中数据计算及分析均 由系统完成, 只需根据图形数据提示完 成放样, 完成记录上传, 并生成电子版 技术交底。 


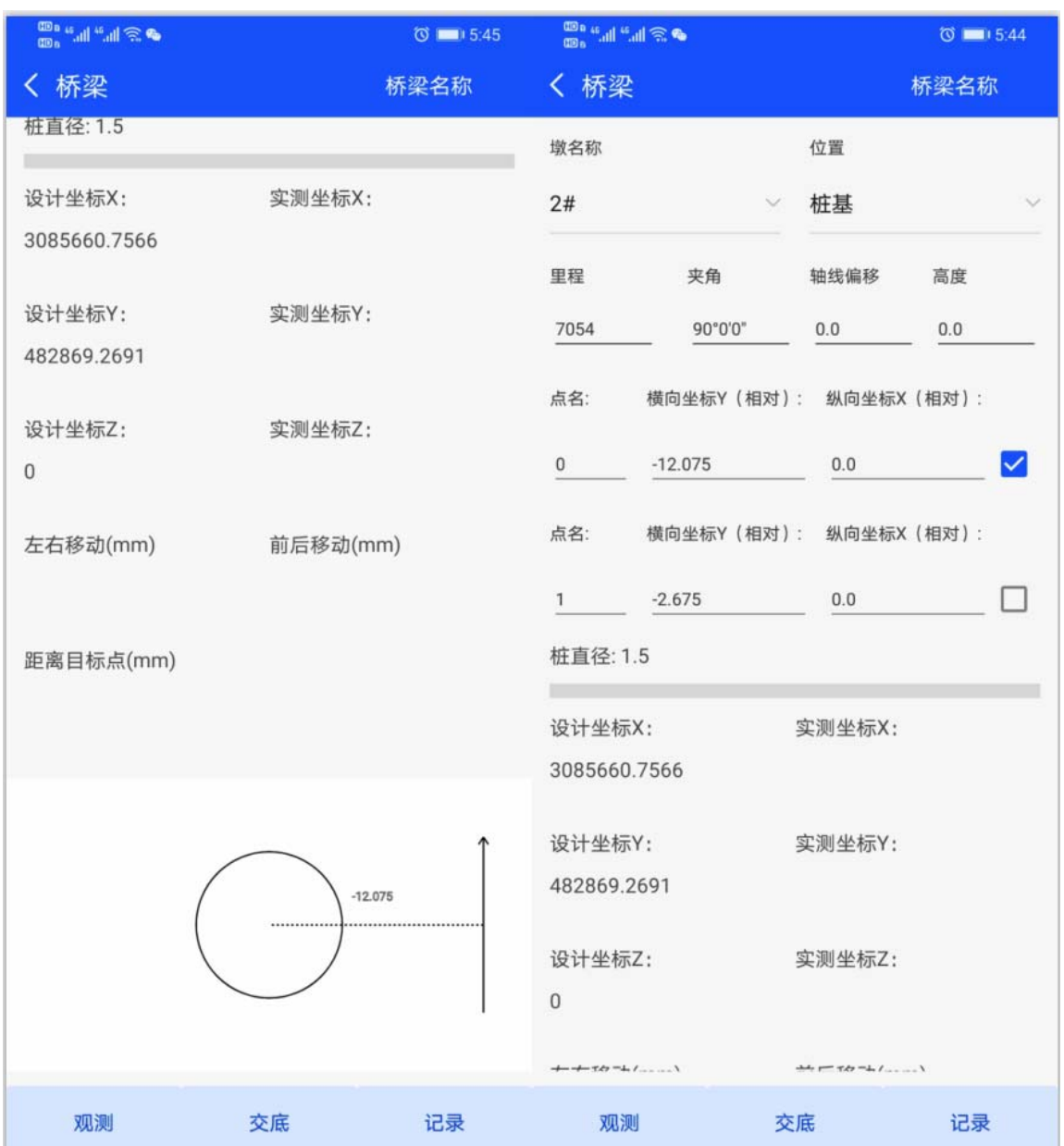

测量软件现场放样界面

本方法在现场放样过程中规范了设 站精度, 保留了设站数据, 在测量放样前 就保证了精度。在放样过程中计算、记 录等都由系统完成, 减少人工记录、计算 的时间, 缩短测量放样时间, 也降低了人 工出错的概率。

\section{2技术交底}

根据放样结果, 传统测量方法, 在固 定格式的技术交底模板中, 表示清楚放 样内容结果, 用于指导现场施工。

应用 “测量信息化管理平台” 放样 完成, 记录上传, 点击交底根据上传记录, 选择内容生成技术交底。

与传统的技术交底相比, 该方法快 速、省时, 一键生成, 节省了纸张, 省去了 纸张技术交底不能长时间保存的困扰, 降低办公耗材的投入。

\section{3 经济效益}

(1) 测量信息化平台可满足所有有 关测量的图纸审核和数据计算, 实现测 量放样数据在线上传, 生成电子版技术 交底, 在线交底的的审批和下发; 应对检 查和日常工作的大量测量记录台帐、报 表、技术交底整理工作由系统完成, 无须 打印, 减少纸质版本的文件打印、装订, 节省了纸张和存放保管费用, 降低办公 耗材的投入。

(2) 测量放样计算和数据记录均有 系统完成, 减少因整理数据和统计分析 数据的人工成本, 以及统计分析错误, 降 低事故的发生率, 从而减少因事故造成 的损失。

(3) 测量信息化平台应用可减少参 与人员、提高设备利用率、缩短测量放 样时间, 减少工期, 提高公司效益。

\section{5 结论}

大桥梁施工放样过程中 “测量信息 化管理平台” 软件相较于传统测量技术 有明显的优势。图纸审核、数据计算建 立常用模板省时高效; 施工放样图形化 信息化显示, 数据计算记录均为系统完 成, 方便快捷; 测量记录保存归档, 技术 交底一步到位; 全部系统化无纸化办公, 减少纸质版本的文件打印、装订, 节省了 纸张和存放保管费用, 降低办公耗材的 投入; 减少人员设备投入, 提高工作效率, 做到精简人员, 降低人工成本。综合考虑, 在桥梁施工放样过程中应用 “测量信息 化管理平台” 具有很好的推广价值。

\section{[参考文献]}

[1]刘涛.公路工程质量检验评定标 准(第一册 - 土建工程) 与施工规范对照 手册:JTG F80/1-2004[M]. 人民交通出版 社,2004.

[2]单位中交第一公路勘察设计研 究院. 公路勘测规范 $[M]$. 人民交通出版 社,2007.

[3]杨瑞.炼化企业测量管理体系信 息化平台的建设 [J]. 计量与测试技 术,2020,47(1):79-82. 